remaining $43 \%$ further investigations were arranged as appropriate. The examination takes place in an unhurried manner (and is preferred by patients to the indirect examination) and the patient may view his own larynx with a teaching attachment. This "feedback" technique is helpful in the management of certain disorders of speech; students may look through this attachment; and a photographic record may be obtained. Nasoscopes, nasopharyngoscopes, sinus scopes, and tracheoscopes are available with the Hopkins rod lens system. With the flexible fibreoptic rhinolaryngoscope, however, there is in one instrument a facility for the examination and photodocumentation of the entire upper respiratory tract. ${ }^{10}$

J M LANCER A S JONES

Senior Registrars in Otolaryngology,

Royal Hallamshire Hospital,

Sheffield S10 2JF

Correspondence to: $\mathrm{Mr}$ Lancer

I Silberman HD, Wilf $\mathrm{H}$, Tucker JA. Flexible fibreoptic nasopharyngolaryngoscope. Ann Otol Rhinol Lanyngol 1976;85:640-5.

Sawashima M, Hirose H. New laryngoscopic technique by use of fibreoptics. 7 Acoust Soc Am 1968;43:168-9.

Davis NJ. A new fibreoptic laryngoscope for nasal intubation. Anesth Analg 1973;52:807-8.

4 Silberman HD, Tucker JA. Examination of the paediatric upper airway with the flexible nasopharyngolaryngoscope. Adv Oto Rhino Lanyngol 1978;23:87-96.

Silberman HD. The use of the flexible fibreoptic nasopharyngolaryngoscope in the paediatric upper airway. Otolaryngol Clin North Am 1978;11:365-70.

6 Williams GT, Farquharson IM, Anthony J. Fibreoptic laryngoscopy in the assessment of laryngeal disorders. F Laryngol Otol 1975;89:299-315.

Selkin SG. Flexible fibreoptics and paediatric otolaryngology: a simple technique for examination and photodocumentation. Int $\mathcal{F}$ Pediatr Otorhinolanyngol 1983;5:325-33.

Lancer JM, Jones AS. Flexible fibreoptic rhinolaryngoscopy: results of 338 consecutive examinations. 7 Lanyol Otol 1985:99.771-3.

Welch AR. The practical and economic value of flexible system laryngoscopy. $f$ Lanngol Otol 1982;96:223-7.

0 Lancer JM. Photography and the flexible fibreoptic rhinolaryngoscope. I Laryngol Otol 1986;100:41-6.

\section{Glue ear and speech development}

Has glue ear replaced dyslexia as the popular excuse of middle class parents whose children fail to meet their educational expectations?' Certainly private screening clinics for educational underachievement have reported a $99 \%$ incidence of glue ear in such children, ${ }^{2}$ and we know that the first two years of life are vitally important in the development of speech and thus of learning. A child born with sensorineural deafness requires intensive language therapy in the first two years of life if speech is to develop in any form. A child developing sensorineural deafness in the same period (for example, from meningitis) preserves its language development but develops imperfect articulation.

The harmful effect of conductive deafness on speech was first identified over 20 years ago by Eisen, who called it the quondam (at one time) hard of hearing syndrome. ${ }^{3}$ Numerous articles, mainly by audiologists and educationalists, have supported this concept, ${ }^{4-16}$ and it has been suggested that language development is affected only if conductive deafness (caused, for example, by glue ear) exists in the first two years of life. Thus there is no effect on language if conduction deafness occurs later. ${ }^{12} 13$

What level of deafness gives rise to language impairment? Most authors favour 25 decibels as the lower limit but some feel that this should be set at $15 \mathrm{~dB}$; thus children who are more than 15-25 dB deaf in the first two years of life may be at risk of impaired language development and thus learning difficulties. Most experts hold that language problems persist into later life and cause irremediable language learning defects, ${ }^{17} 18$ and only one study has suggested that children might subsequently close the language gap. ${ }^{16}$ Speech and language impairment is also more evident in children in higher social classes than in lower ones.

Since infantile sensorineural deafness certainly affects speech development, the notion of a causal relationship between conductive hearing loss and deficient language development is intuitively appealing. If this were established then the already large number of myringotomies performed for childhood deafness might increase. Because of these implications, therefore, research must be conducted in the most rigorous and exacting fashion and unfortunately this has not always been the case. The most serious methodological flaw is in the selection of subjects. Most series have included only a small number of subjects, who have not been matched for age, sex, intelligence, environmental stimulation, race, maturation, or language experience in the home. One or more of these variables might account for any group differences as well as or instead of the conductive deafness. Again, the audiological data have often been inadequate. Audiometry on children is very difficult, especially if $15 \mathrm{~dB}$ is taken as the lower limit. To get a child aged under 5 to respond reliably to less than $15 \mathrm{~dB}$ is extremely difficult and usually the lack of audiological data does not allow its statistical treatment to be assessed adequately.

There has also been inadequate consideration of the conditions associated with otitis media during the first three years of life. Children with recurrent ear problems usually have other upper respiratory symptoms due to infection of, or obstruction by, tonsils and adenoids. They frequently miss play sessions at the nursery or the school, thus being deprived of language stimulation. When their ability to live and learn is interfered with periodically by chronic illness, it is not surprising that they should be behind their peers not only in language development but in all facets of learning.

Is glue ear, then, a cause of language and learning disorders? On the basis of the present evidence the answer is probably no. There is no need for otolaryngologists and paediatricians to seek out more children aged under 2 for myringotomy. The research required to prove that moderate conductive deafness affects language development is, however, difficult and if the difficulties were to be overcome then even more myringotomies might become necessary.

A G D MARAN Head of Department JANET A WILSON Lecturer

Department of Otolaryngology,

Royal Infirmary,

Edinburgh EH3 9YW

1 Black N. Glue ear; the new dyslexia? Br Med f 1985;290:1963-5.

2 Feinmann J. BUPA's glue ear under achievers clinic arouses controversy. Medical New 1983;15:17.

3 Eisen NH. Some effects of early sensory deprivation on later behaviour: the quondam hard of hearing child. Joumal of Abnormal and Social Psychology 1962;65:338-42.

4 Zinkus PW', Gottlieb MI, Schapiro M. Developmental and psychoeducational sequelae of chronic otitis media. Am $\mathcal{F}$ Dis Child 1978;132:1100-4

Kaplan GJ, Fleshman K, Bender TR, Baum C, Clark PS. Long term effects of otitis media; a 10 year cohort study of Alaskan Eskimo children. Pediatrics 1973;52:577-85.

6 Rentschler GJ, Rupp RR, Presley M. Screening selected auditory defects in speech and language impaired children. $\mathcal{F}$ Aud Res 1980;20:271-8.

Hubbard TW, Paradise JL, McWilliams BJ, Elster BA, Taylor FH. Consequences of unremitting middle ear disease in early life. $N$ Engl 7 Med 1985;312:1529-34

8 Lewis N. Otitis media and linguistic incompetence. Arch Otol 1976;102:387-90.

9 Holm VA, Kunze LH. Effect of chronic otitis media on language and speech development. Pediatrics 1969;43:833-9.

$10 \mathrm{Katz}$ J. The effects of conductive hearing loss on auditory function. ASHA 1978;20:879-86.

11 Northern JL, Downs MP. Hearing in children. 3rd ed. Baltimore: Williams and Wilkins, 1984. 
12 Paradise JL. Management of middle ear effusion in infants with cleft palate. Ann Otol Rhinol Lanyngol 1976;85:285-8.

13 Teele DW, Klein JO, Rosner BA. Epidemiology of otitis media in children. Ann Otol Rhinol Laryngol 1980;89:5-6.

14 Brondes PJ, Ehinger DM. The effects of early middle ear pathology and auditory perception and academic achievement. I Speech Hear Disord 1981;46:301-7.

15 Kessler ME, Randolph $\mathrm{K}$. The effects of early middle ear disease on the auditory abilities of third grade children. Fournal of the Academy of Rehabilitative Audiolog. 1979;12:6-20.

6 Needleman H. Effects of hearing loss from early recurrent otitis media on speech and language development. In: Jaffe B, ed. Hearing loss in children. Baltimore: University Park Press, 1977:421-9.

17 McKay H, Sinisterra L, McKay A. Improving cognitive ability in chronically deprived children Science 1978;200:270-8.

18 Tampol L, ed. Introduction to learning disabilities. Springfield, Illinois: Charles C Thomas, 1973.

\section{The health of plantation workers}

Plantations are no mere relics of Britain's colonial past. Indeed, many are large thriving agricultural institutions (producing commodities such as tea, tobacco, and rubber) that play a crucial part in their countries' economy. In Zimbabwe a fifth of the working population works on plantations; in Malaya and Sri Lanka the figure is $10 \%$, in India $1 \%$. Among the various definitions of plantation is the telling one of "a social institution that depends on the use of unfree labour." This is a clear reminder that the labour force often consists of the descendants of migrant workers whose rights are few, working conditions frequently grim, education minimal, and health poor-in many instances worse than that of similar workers outside the plantations. Appreciable improvements in the health of the workers on some plantations have been made over the past few years, and this was the theme of a recent conference held at the London School of Hygiene and Tropical Medicine.

The meeting concentrated on new health programmes that have been introduced in plantations run by the United Planters Association in southern India, those managed by the Sri Lanka Planters Cooperation, and farms in Zimbabwe that have participated in the Bindura Farm Health Worker Scheme. An overview of plantation workers in Malaya was also given and yielded the surprising statistic that, although Malaya is by far the richest of the four countries considered, about $55 \%$ of the workers on the large estates still live below the absolute poverty line. (Details of the programmes discussed are available from the Evaluation and Planning Centre for Health Care. ${ }^{1}$ )

Geographical and cultural differences between the countries have dictated different approaches, but certain factors hold true. Firstly, many of the old plantation labour laws need to be updated. Secondly, the medical services on plantations have tended to be exclusively curative, with the doctors often unaware of the conditions under which their patients live and work. Thirdly, the energy and enthusiasm of a handful of people-provided that they have the cooperation of the plantation owner or, if the plantation is state run, the cooperation of key top officials - can achieve impressive improvements in health.
Most schemes have focused on preventive care and maternal and child health. Subsequent improvements in their health have, in some instances, benefited the plantation owners too because often the women do most of the work. The measures that have had most impact include providing antenatal care, building creches near the fields so that women can breastfeed with minimal disruption, and providing supervised preschool care for the under $5 \mathrm{~s}$. These leave mothers physically and emotionally more free to get on with their work and provide an opportunity to screen the children for health problems. Thus whether it is undernutrition or scabies, for example, the families may be approached and advised about feeding practices and treatment.

Crucial to the success of these schemes is the trained farm health worker or linkworker (a variety of names are applied) and midwife, who are trusted members of the community and after a short period of training are well able to give advice on topics such as basic hygiene, family planning, antenatal care, the use of oral rehydration fluids, and immunisation.

Though standards of health may be raised by such methods with minimal expenditure, further improvementfor example, providing a continuous supply of piped water to the workers' houses, a latrine for every family, better schools, new and upgraded accommodation, fairer and regularly increasing wages (all essential if workers are going to obtain autonomy and a reasonable standard of living) - is costly. The improvements described in the health and social status of the plantation workers in Sri Lanka clearly owe much to outside funding from organisations such as the World Bank, the Asian Development Bank, and the Dutch, Norwegian, and British governments.

In a day dominated by the achievements of a few in improving the health and social status of many, several questions were unanswered: what is the true cost of implementing and maintaining such schemes; do they continue to work when the key figures move on; to what extent, if any, are Western ideas of health integrated with indigenous systems of medicine; is the framework for evaluating the success of such health care projects adequate?

By implication the answer was no-we cannot claim to have an ideal framework in Britain. Nevertheless, most plantations keep scrupulous records, and the standard health indices are usually measured accurately. Talking to local people and holding focus groups among them to see how their ideas and expectations have changed also provide some measure of the success of a programme.

Those who would like to know more about health policy on plantations should contact Dr Richard Laing, Institute of Development Studies, University of Sussex, Falmer, Brighton BN1 9RE, or Gill Walt, Evaluation and Planning Centre for Health Care, London School of Hygiene and Tropical Medicine, Keppel Street, London WC1E 7HT.

Assistant editor, $B M \mathcal{F}$

TESSA RICHARDS

1 Laing R. Health and health services for plantation workers. London: Evaluation and Planning Centre for Health Care, London School of Hygiene and Tropical Medicine, 1986 